\title{
Recrutamento e Publicidade
}

\author{
Neusa Feital WöhrLe, \\ (Técnico de Educação)
}

\begin{abstract}
A
Divisão de Seleção e Aperfeiçoamento do D.A.S.P. está interessada na execução de um programa de recrutamento que utilize os recursos modernos de divulgação dentro das téčnicas de Relações Públicas. Com o objetivo de imprimir a êste trabalho um sentido utilitário e prático, foram estudadas as pcssibilidades atuais da D.S.A., de modo que se condicionem as sugestões apresentadas, na parte final, à legislação $€ m$ vigor, aos recursos orçainentários e ao quadro de pessoal.

De dezembro de 1942 a janeiro de 46, existiu uma Seção de Recrutamento, cujas funções estão definidas no artigo 29 do Decreto-lei n. ${ }^{\circ} 11.101$, de 11-12-1942:
\end{abstract}

"Ā Seção de Recrutamento compete propor e tomar providências destinadas à criação, manutenção e desenvolvimento dos mercados de trabalho, devendo, inclusive:

I - informar permanentemente o público, pelos meios de divulgação aconselháveis, sôbre as vantagens do serviço público como carreira;

- II - promover, por meio de anúncios, cartazes, folhetos e notícias radiofônicas, ampla divulgação das oportunidades que se apresentem no serviço público, inclusive abertura de concursos e provas de habilitação;

III - manter-se em contato com estabelecimentos de ensinu. associações profissionais, técnicas ou culturais, sindicatos, institutos de orientação profissional e quaisquer outras fontes de recrutamento, fazendo, junto a êles, a propaganda das oportunidades que se ofereçam no serviço público;

IV - orientar os candidatos à função pública; e

$\mathrm{V}$ - manter registro das pessoas que se mostrem interessadas ou que pareçam habilitadas a certos tipos de trabalho $\epsilon$ comunicar-1hes as oportunidades que se oferecerem".

Algumas dessas funções, previstas em lei, foram executadas com certa precaridade de recursos. Estabeleceram-se contatos com escolas e repartiçõés públicas; fêz-se alguma publicidade jornalística e radiofônica sôbre as oportunidades oferecidas pelo serviço público; planejou-se um levantamento do mercado de trabalho através dos anúncios de empregos, publicados em todos os 
jornais do país; tentou-se aconselhamento de candidatos reprovados em concurso através do cartas e do estudo dos casos de deficiências em determinadas disciplinas, publicaram-se folhetos e organizou-se uma exposição sôbre o sistema do mérito. (1)

Em 24-1-1946, foi extinta a Seção de Recrutamento (Decreto-lei número 20.489). Algumas de suas funções ficaram afetas às seções de Planejamento e de Inscruções, tendo sofrido apreciável redução o trabalho de recrutamento pròpriamente dito.

Os que se dedicam ao estudo da Administração do Pessoal reconhecem que "nenhum elemento é mais importante no serviço público do que o recrutamer.to". (2) A utilização cada vez mais aperfeiçoada dos recursos da imprensa e das artes gráficas, do rádio, do cinema, da televisão, de exposições, conferências, comícios, visitas, contatos formais e informais com indivíduos, corn grupos de pressão e com o público em geral é uma das características de nossos dias. Estará o serviço público utilizando os meios áudio-visuais a seu alcance para influenciar a opinião e formar atitudes do cidadão comum, dos grupos políticos, profissionais, religiosos, econômicos, das maiorias e das minorias, no sentido de obter maior receptividade para seus trabalhos? Não será necessário chegar aos extremos satirizados por ORWELL em seu famoso livro "Mil Novecentos e Oitenta e Quatro", às garras de aço de um Estado poderosíssimo, das quais não se pode evadir nem o corpo, nem a alma, nem a vontade, nem, o pensamento do indivíduo", (3) ou ao rigor do condicionamento de reflexos para fins de propaganda, aos requintes maquiavélicos da técnica estudada por Tchakhotine em "Le Viol des Foules par la Propaganda Politique". (4) A publicidade administrativa ter-se-á de firmar nos mais sadios ideais de valorização do indivíduo e do bem estar comum.

Quem quer que se detenha a comparar o que se faz entre nós no terreno da propaganda comercial e da publicidade administrativa, há de verificar que os métodos da primeira diferem substancialmente dos da segunda. Folheemos um jornal e comparemos as notícias oficiais com a propaganda comercial; liguemos nossos receptores de rádio e estabeleçamos paralelo entre os programas patrocinados pelo comércio e a indústria e os mantidos por entidades governamentais. O que nos chama logo a atenção é o fato de ser mais atraente a propaganda comercial. Por que? Deixando de lado fatores importantíssimos, como sejam, no caso das publicações o aspecto gráfico, e, nos programas de radiodifusão, os recursos sonoros, para focalizarmos, apenas, a linguagem, verificamos que a publicidade administrativa é, quase sempre, pouco atraente, muito formal, sem interêsse humano e, às vêzes, inaccessivel ao cidadão comum. Poucos setores serão mais atingidos por êste estado de coisas, do que o recrutamento.

(1) Relatório do D.A.S.P. - Imprensa Nacional, 1943 e informações fornecidas pelo Prof. Roberto MOREIRA, ex-chefe da Seção de Recrutamento.

(2) Mosher, William E., - Public Personnel Administration, New York \& London, Harper \&6 Brothers, 1941.

(3) ORWELL, George, - Nineteen Eighty-Four, London, Sucker 86 Warburg, 1950.

(4) Tchakhotin, Serge, - Le Viol des Foules par la Propagande Politique, Paris, G. Pallimard, 1952. 
O levantamento bibliográfico que aparece no fim dêste trabalho, revela haver entre nós, desde alguns anos, um clima favorável à execução de um programa de recrutamento que vise a atrair ao serviço público não sòmente "os mais capazes", mas os "ótimos entre os melhores". (5) Para que isto se torne realidade, é necessário que, a par de publicidade em moldes atualizados, hajia uma boa política de Administração do Pessoal. Em que consistirá essa boa política? Em têrmos gerais, no conjunto de medidas que atendam aos motivos básicos do indivíduo e aos ideais da sociedade em que vive. Citaremos de passagem algumas daquedas medidas, chamando a atenção para os efeitos psicológicos das mesmas: a classificação de cargos, as tabelas de salários ajustadas à realidade econômica, os planos de previdência, o processo de seleção, as oportunidades de aperfeiçoamento, a integração do indivíduo ao grupo de trabalho, o emprêgo útil das horas de lazer, a existência, enfim, de condições que permitam ao indivíduo obter satisfação das atividades profissionais, desenvolvendo vários aspectos de sua personalidade e contribuindo para o progresso social.

Sem o arcabouço sólido de uma política de pessoal, sadia e progressista, qualquer esfôrço para a execução de um programa de recrutamento sofrerá tremendas limitações. Entre nós, um dos grandes entraves da Administração de Pessoal é a diferença entre a situação de direito e a situação de fato. $\mathrm{O}$ sentido de frustação e insegurança que tal fato acarreta constitui nota permanente de mal estar no serviço público. Além disso, deve-se considerar a falta de uniformidade nos critérios adotados por diferentes setores da administração para solucionar problemas idênticos. Esse fato ocorre freqüentemente em jurisdições que atuam sôbre a mesma área geográfica e sôbre o mesmo cidadão. E o mal estar, evidentemente, se agrava. Todos conhecemos inúmeros exemplos em que a administração federal, a estadual e a municipal dão tratamento diferente aos mesmos problemas. E' claro que a opinião pública tende a aceitar as soluções que estiverem mais de acôrdo com suas conveniências imediatas e seus padrões culturais. Observemos o que se tem passado na capital do país e nas principais cidades depois do movimento renovador no serviço público federal, no que diz respeito à implantação do sistema do mérito. Parece haver uma situação permanente de conflito, de quando em quando agravado, entre os que desejam institucionalizar o sistema do mérito e os que investem contra o mesmo. Êsses últimos organizam-se em grupos de pressão, fazem campanhas de imprensa, cabalas nos corredores do Congresso, pressão junto ao Executivo, recursos ao Judiciário no sentido de não se submeterem aos vereditos do sistema do mérito. Muitas e muitas vêzes são bem sucedidos. As causas e conseqüências dessas duas atitudes opostas - a dos que defendem e a dos que atacam o sistema - só podem ser analisadas à luz da tradição histórica brasileira, dos padrões de conduta e dos valores éticos, objeto de estudo da Psicologia, da Sociologia e da Antropologia. Seria interessante pesquisar-se se, para o homem comum, um nome de família, o prestígio político, a fôrça eleitoral, os laços de amizade constituem ou não fatores mais importantes do que a capacidade profissional.

(5) Siqueira, Belmiro - Política de Recrutamento, in "Revista do Serviço Público", D.A.S.P., 1950, V. 2, abril, n. ${ }^{\circ} 1$, pág. $60 / 1$. 
Há dias contou-me a Prof. Stella Pessanha o seguinte fato, ocorrido numa de nossas escolas superiores: o professor de grande nomeada, verificando ter atribuído nota sofrível à prova da aluna considerada ótima, justificou-se dizendo: "Como é possivel julgar provas que não são assinadas?"... O caso dispensa comentários.

Para bem compreender atitudes dêsse tipo, vale a pena recordar as observaçôes de Walter Lippman em seu trabalho pioneiro sôbre o mecanismo do pensamento estereotipado: "Não vemos primeiro para depois definir; definimos primeiro e depois vemos". (6) O julgamento subjetivo tem prioridade sôbre o fato objetivo:

Se considerarmos a instituição do sistema do mérito fase evolutiva da Administração do Pessoal e se admitirmos a circunstância de não ocorrer, ao mesmo tempo, em todos os setores, nem obter a aprovação de todos os indivíduos, estaremos melhor armados para enfrentar as dificuldades que sempre surgem contra sua implantação. Seria lírico esperar grande receptividade para um sistema que contraria, muitas vêzes, interêsses egocêntricos e não se harmoniza com os valores morais do grupo sôbre o qual atua.

Numa conferência pronunciada na Escola Brasileira de Administração Pública, o Prof. Temístocles Cavalcanti contou ter ouvido, numa reunião nas Nações Unidas, o seguinte comentário de um professor norte-americano: "Perdemos a China por não sabermos Antropologia"... Poderíamos para frasear afirmando: temos de conhecer melhor as ciências sociais para implantar o sistema do mérito no Brasil. Temos de indagar se os padrões morais e os conceitos éticos sôbre os quais êle se firma são valores integrados no comportamento do cidadão comum, dos grupos de pressão, dos legisladores, dos que influenciam a opinião pública, dos que dispõem de qualquer parcela de poder. A aceitação que possa aparentemente existir representará uma crença no valor do sistema ou será resultado de atitude racionalizada para salvar aparências? Até que ponto essa atitude é vulnerável às investidas dos outros processos de julgar?

Êsses comentários ocorrem-nos no momento em que nos dispomos a delinear uma campanha de recrutamento; porque, apesar do muito que se tem escrito sôbre publicidade, não será demais repetir que o indivíduo é o seu centro de interêsse. $\mathrm{E}$ o indivíduo exatamente como é e não como o idealizamos. Ao redigirmos uma nota para jornal, a legenda para uma fotografia, o texto de um folheto, de um cartaz, o escrito (script) de um programa de rádio ou de televisão é ao indivíduo que levaremos nossa mensagem publicitária. O toque pessoal, o interêsse humano, o conteúdo emotivo são o primeiro passo para o sucesso de nossos propósitos.

A execução de um plano de recrutamento positivo, isto é, aquêle que visa a atrair os mais aptos e não se detem exclusivamente nos esforços para afastar os ineptos, precisa utilizar todos os recursos disponíveis de divulgação. Cada grupo social e econômico, cada área geográfica, cada tipo diferente de agrupamento e cada indivíduo apresenta maior receptividade a determinado meio

(6) LippmanN, Walter, - Public Opinion, New York, the Macmülan Company, 1922, pg. 81 . 
de comunicação. Não poderemos utilizar indiferentemente a imprensa, o rádio, o cinema ou a televisão, porque cada um dêsses recursos têm sua clientela típica. Para que uma campanha de divulgação se realize eficientemente é necessário recrutar profissionais capazes de empreendê-la. Que tipo de babilidades deverão ter? Onde poderão ser encontrados?

Em todo o mundo publicidade é assunto novo que vem sofrendo espantoso impulso nos últimos dez anos. A multiplicidade de talentos exigidos ainda não permitiu articulação perfeita entre os cursos de treinamento e as necessidades práticas. Há sempre aproveitamento dos que exercem profissões afins e improvisação dos que têm certa versatilidade. Assim, a televisão recrutou profissionais do rádio e do cinema; êstes, os da imprensa e das artes gráficas; por sua vez estas já haviam batido às portas da literatura, das artes e do urtezanato. As agências de publicidade precisam do trabalho criador de pıosadores $€$ poetas, de desenhistas e músicos, de fotógrafos, cinegrafistas, homens de rádio e televisão, além da capacidade profissional de pesquisadores de cpinião pública, de conhecedores de problemas de economia. Nas condiçõ.'s atuais do mercado de trabalho é bastante difícil a organização de um órgão de publicidade no serviço público. A solução talvez consiste no desenvolvimento de talentos em potencial, no aproveitamento de redatores, desenhistas, cios que trabalham no cinema e no rádio oficiais, na articulação dos esforços que vêm sendo feitos por algumas entidades públicas e particulares para a ręlização de pesquisas sociais e econômicas que orientem a ação dos que se cispuserem a fazer publicidade administrativa. Um trabalho de equipe se faz indispensável e a liderança dessa atividade só poderá caber a um conhecedor dos problemas de Administração do Pessoal que dos mesmos tenlıa concepção generalista. Embora o trabalho de recrutamento, muitas vêzes, tenha objetivos imediatíssimos, como seja, atrair candidatos para deterninado cargo que precisa ser preenchido com a maior premência de tempo, sua filosofia deve encerrar cogitações muito mais amplas. Cumpre aumentar o respeito ao serviço público, apelando para razões de satisfação individual, procurando conciliá-las com os motivos cívicos; estimular os indivíduos e os : yrupos profissionais com o exemplo dos funcionários bem sucedidos; despertar 0 interêsse dos jovens nas escolas, articulando a ação do Estado como educador à do Estado como empregador.

Os que se empenharem nessas atividades devem atender ao fato de estarmos vivendo uma época de transições tão violentas e tão rápidas, que precisamos continuamente ajustar o que julgamos ser melhor ao que melhor se enquadra às imposições do momento.

\section{BIBLIOGRAFIA}

AUDARD, J. - O recrutamento e a formação de funcionários. (In "Revista do Serviço Público". D.A.S.P., 1941 v. 1, jan., 350.5 R. 454.

BROWNRIGG, William. - Toward effective recruiting; a method for notifyng qualified candidates of schedinled examinations. (Chicago) Civil service assembly of the United States and Canadá. 1937. F 351.21 B 885.

CARMICHAEL, Leonard. - $O$ cadastro americano do pessoal científico e especializado. (Tradução de Herson de Faria Dória). (In "Revista do Serviço Público". Rio de Janeiro, D.A.S.P., 1948. v. 3, nov.-dez. m. 3-4 p. 78-81). 350.5 R. 454. 
CARPENTER, William F. - The unfinished business, by civil service reform. New Jersey, Princeton University Press, 1952. 128 p. (F.G.V.)

FERNANDES, Maria Joana de Almeida. - O recrutamento e as nomeações interinas. (In "Revista do Serviço Público". D.A.S.P., 1947. v. 3, set.-out. n. 1-2, p. 138-39). 350.5 , R.454, (M.E.C.)

FREDERIC, Katherine A. - State personnel administration... Washington, United States Government printing office, 1939. 351.2 F.852.

FreITAS, Byron Torres de - Administração de pessoal. Rio de Janeiro, Editora Panamericana Ltda., 1945. 351.2 F. 866.

HERCHOW, Reuben - Machines in civil service recruitment, with special reference to experiences in Ohio. U.S.A. civil service assembly, 1939. 351.21 H. 811 (M.E.C.)

JUBÉ, Joaquim R. Ramos de - O teste objetivo de área específica no recrutamento do pessoal para as carreiras técnicas científicas (In "Revista do Serviço Público". Rio de Janeiro, D.A.S.P., 1941, v. 1, fev. n. 2, p. 52-7) 350.5 R. 454 (M.E.C.)

Mosher, William E. - Public personnel administration. New York and London, Harper \& Brothers publishers, 1941. 351.2 M. 911.

NAtional Association of assessing offices. - Assessment organization and personnel. Chicago, National Association of assessing officers, 1941. 351.2 M. 277.

PINTO PESSOA, Eduardo e TEIXEIRA DIAS, J. Nazareth - Principios de administração de pessoal. Rio de Janeiro, Imprensa Nacional, 1949. 351.2 P. 475.

RAMOS, Arlindo Vieira de Almeida - Recrutamento e cultivo das fontes de provisão de pessoal. (In "Revista do Serviço Público". Rio de Janeiro, D.A.S.P., 1942. v.4, n. 3 p. $41-53350.5$ R. 454.

SrqueIRA, Belmiro - Política de recrutamento. Diretrizes. (In "Revista do Serviço Público". D.A.S.P., v. 2, abril, n. 1, p. 60-1.

Siqueira, Belmiro - Recrutamento e seleção. (In "Revista do Serviço Público". D.A.S.P., 1946. v. 3, agôsto-setembro, n. 2-3 p. 108-10.

TORPEY, William - Public personnel management. Toronto, etc. D. van Nostrand Company inc., 1953. 351.2 T. 686 .

\section{SUMMARY}

The Division of Selection of the Dasp (Administrative Department of Public Service) and the implementation of a recruitment policy based on the utilization of modern media of communication and of the techniques of public relations. Legislation on recruitment policies (1942-46) reviewed. The programme of the recruitment unit. Importance of a recruitment policy aiming essentially at the selection of the best candidates among the applicants, rather than at the refusal of less qualified persons.

Current events, pamphlets, dodgers, broadcasting and T.V. programmes, exhibitions, lectures, debates visits, formal and informal contacts with individual and pressure groups utilized as means of personnel selection. Commercial propaganda and administrative publicity contrasted. Personnel administration and recruitment programmes. The merit system in Brazil. Cultural set-up and histcrical tradition; their role in the implementation of the system.

Tra história da nossa pátria, o Itamarati não só encarna a vigilância na defesa da unidade, da integridade e da soberania da nossa pátria, mas é ainda o elo de união que mantém estreita a amizade do Brasil com a família dos povos entre os quais aspira viver em paz e com dignidade.

(In discurso do R. P. Revmo Pe Pedro Veloso, Pontifícia Universidade Católica). 